\title{
Differences between fertility desires and intentions: implications for theory, research and policy ${ }^{1}$
}

\author{
Warren B. Miller*
}

\begin{abstract}
In previous research I have theorised that there is a three-step motivational sequence that drives fertility behaviour, beginning with motivational traits, continuing with fertility desires and concluding with fertility intentions. In this article I focus on four properties of fertility desires and intentions, examining some recent research findings that bear on the similarities and differences between these two constructs. The four properties include the degree to which either construct has direct genetic antecedents, the degree to which either construct directly predicts behaviour, what type of dimension is used to measure each construct, and the effects that each construct has on the individual's satisfaction with being pregnant. The findings regarding these four properties suggest that fertility desires are intermediate between two evolutionally distinct motive systems that drive reproductive behaviour. The findings also suggest additional research questions that require further pursuit. Finally, the findings inform certain fertility-related policy issues, in particular the gap between desired or intended fertility and actual fertility.
\end{abstract}

\section{Introduction}

There is a two-fold problem in the research literature with respect to the constructs of fertility desires and fertility intentions. First, the terms are often used interchangeably. There are probably a number of reasons for this conflation, including conceptual confusion as a result of inadequate or poor construct definitions, the presence of one or the other term, but rarely both, in large, survey-

\footnotetext{
1 This article is based on an invited presentation at the conference "From intentions to behaviour: reproductive decision-making in a macro-micro perspective" organised by the Vienna Institute of Demography and the international project REPRO and held in Vienna, Austria, on December 2-3, 2010.

${ }^{*}$ Warren B. Miller, Transnational Family Research Institute, 229 Wixon Avenue, Aptos, California, 95003-4626 USA. Email: rennie@tfri.org
} 
based databases that are frequently used by investigators, and the fact that the distinction between them may be awkward or confusing in some languages. The second problem is that there has been a research emphasis on intentions, despite the unique and important properties of desires. This emphasis is partly because intentions are the most proximate component of the motivational stream that leads to behaviour and partly because there is a highly useful and well developed theoretical framework available for understanding how intentions work, namely the Theory of Planned Behaviour (Ajzen 1991, 2005). In this article I will summarise some recent developments in my motivationally based model of fertility with the goal of describing some of the important differences between the constructs of desires and intentions and discussing some of the implications that these differences have for fertility theory, research and public policy.

\section{Background}

Much of the research I conducted during the 1990s focused on the motivational antecedents to childbearing and made use of a Traits-Desires-IntentionsBehaviour (T-D-I-B) theoretical framework. The basic idea of that framework is that the motivational forces driving the fertility-related behaviours of individuals and couples unfold in a sequential process that begins with non-conscious motivational dispositions (traits) to have or not have children, which lead to conscious desires to have children or not, which in turn lead to conscious intentions to have children or not, which finally lead to the performance of behaviours that are instrumental in the achievement or avoidance of the childbearing. Although this framework proved useful, it was also essential for predictive purposes that each of its four components be further elaborated. Thus motivational traits can be divided into positive and negative motivations (Miller 1995); desires can be divided into childbearing, child-number and child-timing desires, intentions can be divided into the corresponding three components (Miller 1994; Miller and Pasta 1993, 1994) and behaviour can be divided into its proceptive (Miller 1986) and contraceptive (Miller and Pasta 1996) forms.

Figure 1 shows the predictive relationships included in this expanded T-D-I-B model. The reasoning behind most of the model pathways is self-evident. I assume that the coefficients of positive and negative childbearing motivations have opposite signs and that the same is true for the predictors of proceptive and contraceptive behaviours. The reasoning behind the child-number and childbearing variables predicting the child-timing variables can be summarised as follows: the more children one desires/intends and the stronger one's childbearing desires/intentions are, the sooner one desires/intends a(nother) child. 
Figure 1:

An expansion of the T-D-I-B model to show the interactions of two types of traits, three types of desires and three types of intentions in their effect on two fertility behaviours and the probability of any subsequent fertility events

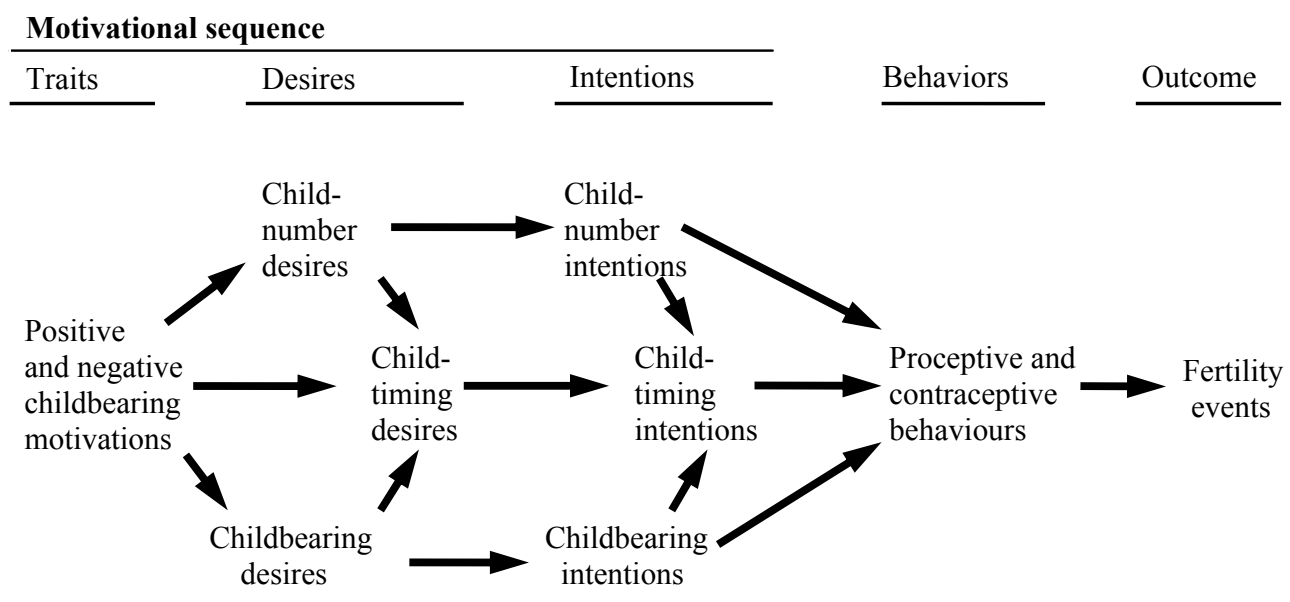

Note: Adapted from Miller (1994)

A large part of my work during the last decade has focused on conceptualising the biological basis for the motivational traits that drive reproductive behaviour. Because of the critical importance of reproduction for species survival, I have assumed that every individual has a large and complex, genetically determined and diffusely distributed set of neural connections within the central nervous system (CNS) that assures effective reproductive behaviours. I have further assumed that that these behaviours involve not just sexuality but the caring for and socialising of any offspring that are produced. This means that such protective and loving behaviours have to be intrinsically rewarding, something that can best be accomplished by bonding schemas. Joe Rodgers and I developed these ideas in a book (Miller and Rodgers 2001) about bonding schemas, which we describe as preadapted groups of neural networks that organise how we perceive, think and feel about, and respond to people in the social environment. We describe four types of bonding schemas, but it is one type in particular, which we called the nurturant schema, that underlies the motivational traits involved in driving fertility behaviours.

Given the biological underpinnings of these traits, the four-step T-D-I-B motivational system may be said to represent the integration of two evolutionarily distinct motive systems, each one uniquely designed to promote successful reproduction. The first is a more primitive system that operates typically in mammals (Miller 2011, Chapter 2) and is driven more automatically by the 
biologically based affects inherent in bonding schemas. The second is a more highly evolved system that operates typically in humans, is driven more cognitively by the decision-making, intentions and plans for implementation of individuals and couples, and is well characterised by the Theory of Planned Behaviour (Ajzen 1991, 2005). Desires may be seen as straddling these two systems, drawing their motive power from the more primitive bonding system but at the same time articulated in terms of actionable goals, similar to the intentions of the more evolved system. In subsequent sections I will present evidence further supporting the dual nature of this system.

\section{Construct properties}

Table 1 lists a number of properties of the three primary motivational constructs that affect fertility. Even though my focus here will be on desires and intentions, I include motivational traits in the table in order to provide a third point of comparison across construct differences. In the discussion that follows, I will emphasise childbearing and child-number desires and intentions. The reason for this emphasis is that much of the fertility-related variance of child-timing desires and intentions comes from their prediction by childbearing and child-number desires and intentions (Miller and Pasta 1994) and much of the remaining variance is based on how childbearing fits or competes with other behavioural domains, such as those related to education, work, health, etc.

The first five construct properties listed in Table 1 are essentially definitional and/or course when our attention is on other matters, at which time they are out of awareness or in our unconscious mind. On the other hand, motivational traits are dispositions to be motivated by features of the world around us. We are not aware of the traits themselves but rather of the feeling we have in response to the realworld features we encounter. Therefore, such traits may be described as nonconscious, although all of us may become aware that we possess certain traits through self-observation. A clear difference between desires and intentions is that the former simply reflect a wish to achieve a goal through some sort of action, whereas intentions involve a specific decision to pursue an actionable goal, with an associated commitment and, commonly, a plan for implementing the decision. Finally, the three motivational constructs may be seen theoretically as resulting from the different levels of integration by the executive functions of the CNS that are briefly described in the table.

One of the difficulties with the research literature dealing with fertility desires and intentions is the many different ways that these constructs have been measured by different investigators. In my own work I have typically used two separate and somewhat different interview questions to measure each construct. Before asking these questions I tell the respondents that in this research I make a distinction between what someone wants and what they actually intend and 
explain that wanting is based on someone's feelings, whereas intending implies both a commitment to act and is often based on the person's situation, including what someone else wants. Then I measure childbearing desires by asking the respondents the following stem question, "Which of the following five statements best indicates how you feel about having a(nother) child? I definitely want to have a(nother) child; I mostly want to have a(nother) child; I am not sure whether or not I want to have a(nother) child; I mostly want not to have a(nother) child; and I definitely want not to have a(nother) child." Next I ask them to rate on a 10-point scale how much they want a(nother) child, where a 1 indicates not wanting a child at all and a 10 indicates wanting a child as much as possible. The responses to these two questions are then combined in one variable after adjusting the responses to the first question so that it has the same directionality and equal weighting. The same procedure is followed when asking about intentions except that the stem question is about whether or not they actually intend to have a(nother) child, with the five response categories reworded appropriately, and the 10-point rating scale asks the respondents to rate how much they intend to have a(nother) child sometime in the future. These illustrations should give a more concrete indication to the reader, very much as they do to the research respondent, what the desires and intentions constructs mean. Of course, when one is analysing data that were collected by other researchers, the wording of the relevant questions will typically be different and thus the concrete meaning of the measured constructs can vary. As a result, it is incumbent upon the researcher to take these variations into account when planning and interpreting the research.

The next two construct properties are related to measurement and the final five reflect the result of empirical studies. For this final group I have roughly estimated either a modal value for the property and/or a typical value range. There is a great deal of material listed in the table under these seven properties, much more than can be discussed here (see Miller 2011, Chapter 3). In order to provide some empirical support for the dual systems of motivation implicit within the T-D-I-B framework and the implications this duality has for construct differences between desires and intentions, I will focus my subsequent discussion on three of the construct properties based on empirical studies and one of the measurementrelated construct properties. Specifically, I will consider two separate studies of genetic antecedents to desires and intentions (construct property 9 in Table 1), a study that has demonstrated some direct effects of desires on long-term fertility outcomes (construct property 11 in Table 1), a study that uses two unipolar dimensions of desires to predict unintended pregnancy (construct property 7 in Table 1), and finally a study of how desires and intentions affect fertility satisfaction (construct property 12 in Table 1). 
Table 1:

A cross-tabulation of the three motivational constructs in the T-D-I-B framework with different construct characteristics. Adapted from Miller (2011)

\begin{tabular}{|c|c|c|c|}
\hline Construct properties & Traits & Desires & Intentions \\
\hline 1. Construct type & $\begin{array}{l}\text { Motivational } \\
\text { disposition }\end{array}$ & Motivational state & Motivational state \\
\hline 2. Related constructs & $\begin{array}{l}\text { Attitudes, values, } \\
\text { and tastes }\end{array}$ & $\begin{array}{l}\text { Preferences, likes, } \\
\text { and ideals }\end{array}$ & $\begin{array}{l}\text { Expectations and } \\
\text { goals }\end{array}$ \\
\hline $\begin{array}{l}\text { 3. Relationship to } \\
\text { consciousness }\end{array}$ & $\begin{array}{l}\text { Non-conscious but } \\
\text { with self- } \\
\text { observation }\end{array}$ & $\begin{array}{l}\text { Conscious } \\
\text { Unconscious, } \\
\text { Subconscious }\end{array}$ & $\begin{array}{l}\text { Conscious } \\
\text { Unconscious }\end{array}$ \\
\hline $\begin{array}{l}\text { 4. Relationship to } \\
\text { external world }\end{array}$ & $\begin{array}{l}\text { Situational } \\
\text { stimulation of } \\
\text { schema-based } \\
\text { affects that propel } \\
\text { action }\end{array}$ & $\begin{array}{l}\text { A wish to achieve an } \\
\text { actionable goal }\end{array}$ & $\begin{array}{l}\text { A decision-based } \\
\text { commitment to } \\
\text { pursue an actionable } \\
\text { goal with an } \\
\text { implementation plan }\end{array}$ \\
\hline $\begin{array}{l}\text { 5. Role of CNS executive } \\
\text { function }\end{array}$ & $\begin{array}{l}\text { Integrates affects, } \\
\text { memories, special } \\
\text { cognitions into } \\
\text { bonding schemas }{ }^{1}\end{array}$ & $\begin{array}{l}\text { Integrates schema- } \\
\text { based motivational } \\
\text { traits into desired } \\
\text { actionable goals }\end{array}$ & $\begin{array}{l}\text { Integrates within- } \\
\text { and cross-domain } \\
\text { goals into a decision } \\
\text { with commitment } \\
\text { and a plan }\end{array}$ \\
\hline 6. How measured & $\begin{array}{l}\text { Rate motives or } \\
\text { feelings on multiple } \\
\text { items: explicit } \\
\text { Projective test: } \\
\text { implicit } \\
\text { Behavior composite: } \\
\text { implicit }\end{array}$ & $\begin{array}{l}\text { Rate dimensions of } \\
\text { desire for actionable } \\
\text { goal }\end{array}$ & $\begin{array}{l}\text { Rate dimensions of } \\
\text { intention, } \\
\text { commitment, and } \\
\text { plan for } \\
\text { implementation }\end{array}$ \\
\hline $\begin{array}{l}\text { 7. Childbearing } \\
\text { dimensions measured }\end{array}$ & $\begin{array}{l}\text { Unipolar positive } \\
\text { Unipolar negative }\end{array}$ & $\begin{array}{l}\text { Bipolar } \\
\text { Unipolar positive } \\
\text { Unipolar negative }\end{array}$ & Bipolar \\
\hline 8. Temporal stability & High & Medium to high & Low to medium \\
\hline $\begin{array}{l}\text { 9. Antecedents: } \\
\text { genetic } \\
\text { family environment } \\
\text { unique environment }\end{array}$ & $\begin{array}{l}\text { Strong } \\
\text { Strong } \\
\text { Weak to moderate }\end{array}$ & $\begin{array}{l}\text { Weak to moderate } \\
\text { Moderate to strong } \\
\text { Weak to strong }\end{array}$ & $\begin{array}{l}\text { None to weak } \\
\text { Weak to moderate } \\
\text { Moderate to strong }\end{array}$ \\
\hline 10. Partner effects & None to moderate & Weak to strong & Moderate to strong \\
\hline $\begin{array}{l}\text { 11. Direct effects on } \\
\text { behaviour }\end{array}$ & None to weak & None to moderate & None to strong \\
\hline $\begin{array}{l}\text { 12. Effects on fertility } \\
\text { satisfaction }\end{array}$ & $\begin{array}{l}\text { Mostly indirect, } \\
\text { some direct }\end{array}$ & $\begin{array}{l}\text { Mostly direct, some } \\
\text { indirect }\end{array}$ & $\begin{array}{l}\text { Mostly none, some } \\
\text { direct }\end{array}$ \\
\hline
\end{tabular}

Notes: $\mathrm{CNS}=$ central nervous system. ${ }^{1}$ See Miller and Rodgers (2001). 
I should note that construct property 10, which involves the effect of partners on individual's desires and intentions, is not considered in this article. These effects are complex and including them would extend the discussion beyond a manageable length. A theoretical treatment of some of this complexity is covered in Miller et al. (2004). When reading the material that follows, readers should bear in mind that the motivations of partners and the difference between two partners' motivations are both relevant to all of the construct properties that are discussed.

\subsection{Genetic antecedents}

In order to explore the extent to which the three motivational components of the T-D-I-B sequence had genetic underpinnings, my colleagues Joe Rodgers, David Bard, David Pasta and I (Miller et al. 2010b) conducted a behavioural genetic analysis of data collected as part of the National Longitudinal Study of Youth (NLSY). Our first step was to fit the expanded T-D-I-B framework shown in Figure 1 to the NLSY data. These data had been gathered by interview from a nationally representative sample consisting of approximately 3700 males and 3900 females. The respondents were 14-21 years old in 1979 when data collection began and 37-45 years old at the 2002 follow-up. We identified certain variables from our model that were available from the NLSY data. In this case, the childnumber desires variable was based on a latent variable composed of four questions about the respondents' desired and ideal number of children and the child-number intentions variable was based on a question about the respondents' child-number expectations. We then used LISREL software (Joreskog and Sorbom 1996) to fit a two-group (males and females) exploratory structural equation model (SEM). The main portion of the final model that is relevant to my discussion of desires and intentions is shown in Figure 2. The grey vertical bar separates the traits, desires and intentions that were measured in the 1979-1982 period from the fertility outcomes that were measured in 2002. The behaviours that occurred between 1982 and 2002 were not measured, the assumption being that the fertility outcomes reflected the net effects of antecedent motivations on unmeasured behaviours. The solid lines in the figures represent the primary hypothesised pathways between variables and the dashed lines represent two nonhypothesised pathways: a direct connection between child-number desires and actual timing of the next child and a direct connection between child-timing intentions and the actual number of children born. For purposes of simplification, the path coefficients are not shown but it is worth noting that the coefficient for the latter pathway has a negative sign and probably represents the combined effects of unplanned pregnancies that occurred sooner than intended and subfecundity that resulted in planned pregnancies occurring later than intended. 
Figure 2:

A portion of the LISREL structural equation model results for the entire NLSY sample, showing the connections between the desires, intentions and fertility outcomes part of the model

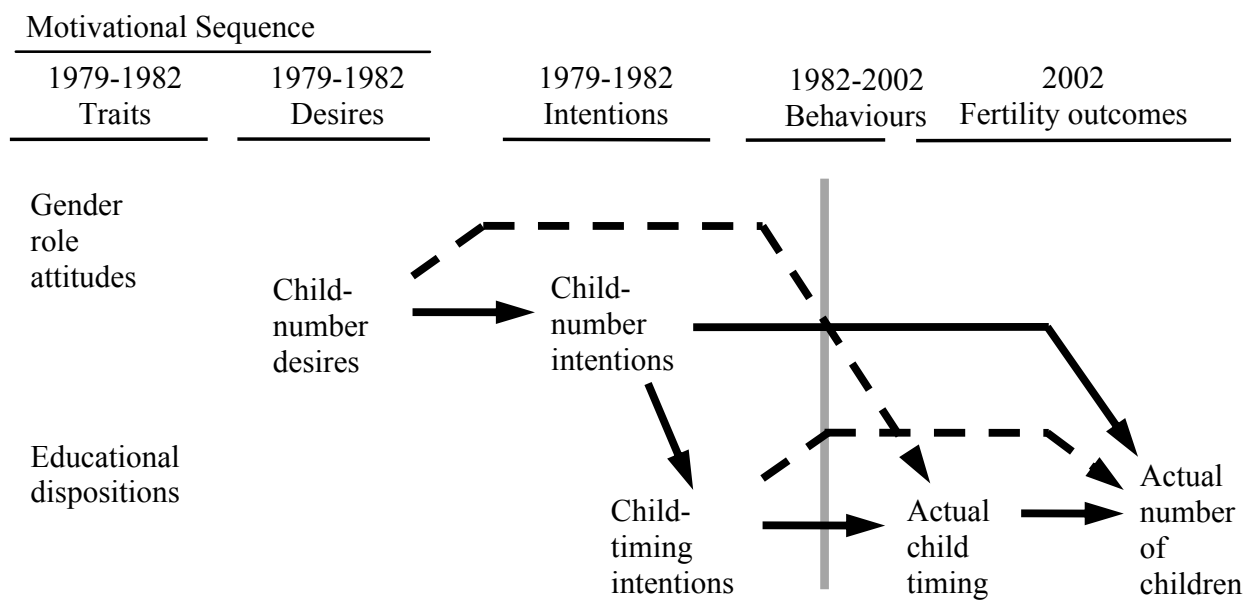

Notes: The grey vertical line represents unmeasured fertility behaviours that occurred during the 1982-2002 interval. Solid lines represent hypothesised connections and dashed lines represent non-hypothesised connections that appeared in the model. Adapted from Miller et al. (2010b)

Our second step was to conduct a behavioural genetic analysis of the phenotypic model shown in Figure 2. The sample for this analysis was restricted to 2,940 males and females who were known to fall into one of five categories of kinship pairs (twins, full siblings, ambiguous siblings, half-siblings and cousins) and where both members of the pair were present in the database. We used the Mx software (Neale et al. 2003) to conduct univariate and multivariate analyses of the kinship data. The results for these two analyses are shown in Tables 2a and $2 \mathrm{~b}$, respectively. Table $2 \mathrm{a}$ shows the proportion of total covariance between kin pairs accounted for by the genetic $\left(\mathrm{h}^{2}\right)$, shared family environment $\left(\mathrm{c}^{2}\right)$ and nonshared environment plus error $\left(\mathrm{e}^{2}\right)$ components. The heritability component $\left(\mathrm{h}^{2}\right)$ equals $70 \%$ for desires and $40 \%$ for intentions.

Table $2 b$ shows the results of a multivariate Cholesky model of the variables in the phenotypic model, time-ordered according to the findings shown in Figure 2. Only the heritability component $\left(\mathrm{h}^{2}\right)$ is shown in the figure. $\mathrm{A}_{1}$ through $A_{6}$ are latent variables. $A_{1}$ is based on all six of the variables indicated in the SEM Variables column on the left, $A_{2}$ is based on the five variables in the SEM Variables column beginning with Child \# Desires, $A_{3}$ is based on the four variables in the SEM Variables column beginning with Child \# Intentions, etc. Because these variables are time-ordered, any $\mathrm{h}^{2}$ observed in a column other than that associated with the primary (top) variable represents heritability passed 
through from that primary variable. Every variable has an opportunity to act as a primary variable. In the gender role attitudes latent variable $\left(A_{1}\right)$, there is a modest $h^{2}$ associated with gender role attitudes. In the child-number desires latent variable $\left(\mathrm{A}_{2}\right)$, there is a substantial $\mathrm{h}^{2}$ associated with the child-number desires variable and two of the variables that are causally affected by it. In the childnumber intentions latent variable $\left(\mathrm{A}_{3}\right)$, there is no $\mathrm{h}^{2}$ associated with child-number intentions. These multivariate findings indicate that there is genetic heritability for Child \# Desires but not for Child \# Intentions and that the univariate finding of heritability for Child \# Intentions shown in Table 2a results from its being temporally (and, presumably, causally) secondary to Child \# Desires.

In another study, David Comings, Jim MacMurray and Donn Muhleman joined with me and David Pasta (Miller et al. 2000) to conduct a molecular genetic study of a sample living in the San Francisco Bay area. The theoretical framework used in that study was based on hypothesised relationships between three CNS neurotransmitters, two types of bonding schemas and the traits-desiresintentions part of the T-D-I-B framework (excluding child-timing desires). The sample consisted of 430 European-American males and females. We collected buccal/cheek swabs from each individual. This biological material was then analysed for the presence of three functionally relevant polymorphisms of a cannabinoid and oxytocin receptor and the serotonin transporter. We used personality traits as proxies for affiliative and nurturant bonding schemas.

Figure 3 shows the results of the SEM that we obtained in that study. The model indicates that the neurotransmitter variables primarily predict the schema proxy variables, that the serotonin polymorphism directly predicts negative childbearing motivation, and that the cannabinoid polymorphism directly predicts child-number desires. There is no direct prediction of childbearing intentions.

Table 2a:

Standardised parameter estimates for univariate ACE model components of the seven variables in the phenotypic SEM model

\begin{tabular}{lccc}
\hline SEM Model Variables & $\mathbf{h}^{\mathbf{2}}$ & $\mathbf{c}^{\mathbf{2}}$ & $\mathbf{e}^{\mathbf{2}}$ \\
\hline Gender role attitudes & 0.34 & 0.20 & 0.47 \\
Educational disposition & 0.01 & 0.54 & 0.45 \\
Child-number desires & 0.70 & 0.13 & 0.16 \\
Child-number intentions & 0.40 & 0.05 & 0.55 \\
Child-timing intentions & 0.00 & 0.00 & 1.00 \\
Actual child timing & 0.00 & 0.11 & 0.89 \\
Actual child number & 0.16 & 0.00 & 0.84 \\
\hline
\end{tabular}


Table 2b:

Standardised parameter estimates for Cholesky model component A after constraining the indicators to zero if doing so improved model fit: gender role attitudes model

\begin{tabular}{lcccccc}
\hline \multicolumn{1}{c}{ SEM Model Variables } & \multicolumn{5}{c}{ Standardised A matrix } \\
\hline & $\mathbf{A}_{\mathbf{1}}$ & $\mathbf{A}_{\mathbf{2}}$ & $\mathbf{A}_{\mathbf{3}}$ & $\mathbf{A}_{\mathbf{4}}$ & $\mathbf{A}_{\mathbf{5}}$ & $\mathbf{A}_{\mathbf{6}}$ \\
\hline Gender role attitudes & 0.21 & & & & & \\
Child-number desires & ---- & 0.63 & & & & \\
Child-number intentions & ---- & 0.38 & ---- & & & \\
Child-timing intentions & ---- & ---- & ---- & ---- & & \\
Actual child timing & ---- & ---- & --- & --- & --- & \\
Actual child number & ---- & 0.02 & ---- & ---- & --- & \\
\hline
\end{tabular}

Note: Both $2 \mathrm{a}$ and $2 \mathrm{~b}$ are adapted from Miller et al. (2010b)

Figure 3:

A schematic representation of a model linking three genetic polymorphisms to personality traits and the three motivational components of the T-D-I-B framework

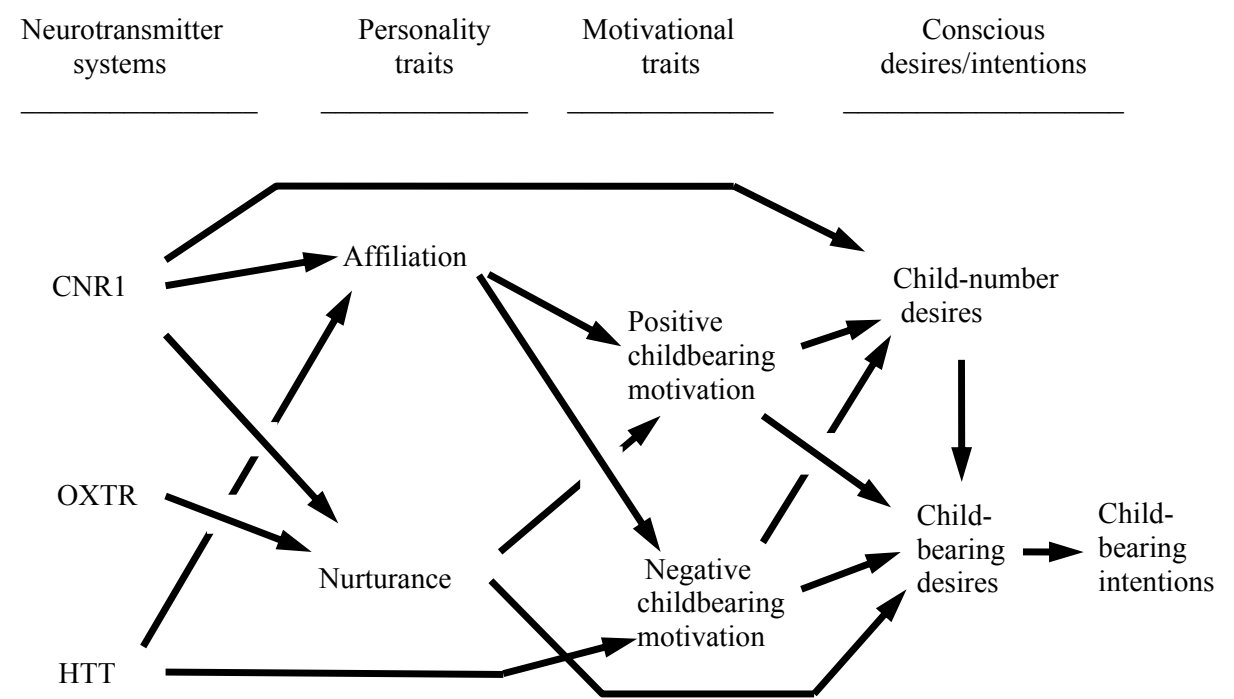

Notes: CNR1, OXTR and HTT indicate variables that measure polymorphisms of, respectively, the cannabinoid receptor, oxytocin receptor and serotonin transporter. Adapted from Miller et al. (2000)

These two studies have important differences: they use data from entirely different samples; they use very different approaches to the study of genetic antecedents, namely a behavioural genetic and a molecular genetic approach; and they arrive at conclusions about different intentions variables, namely childnumber and childbearing intentions. Together they provide good preliminary evidence that whereas child-number desires are directly predicted by certain 
genetic antecedents, this is not true of for child-number or childbearing intentions. This evidence supports my earlier characterisation of the motivational sequence leading to childbearing as a dual system with a strong biologically based affective component, a strong cognitively based decision-making component, and with desires straddling both of these components.

\subsection{Direct effects on behaviour}

In the NLSY study described above in connection with Figure 2, we found that when the theoretical framework was fitted separately to male and female respondents who had no children (parity $=0$ ) in 1982 and those who had at least 1 child (parity $>0$ ) in 1982, the resulting model was different in several interesting ways (Miller et al. 2010a). Figure 4 is like Figure 2 but with the model re-estimated separately for males and females in each of those two parity groups. Again, the solid lines indicate hypothesised pathways, the dashed line represent non-hypothesised pathways, and coefficients are not shown.

\section{Figure 4:}

Four LISREL structural equation models, two constrained across males and females in the no-childbearing subsample and two constrained across males and females in the previous childbearing subsample
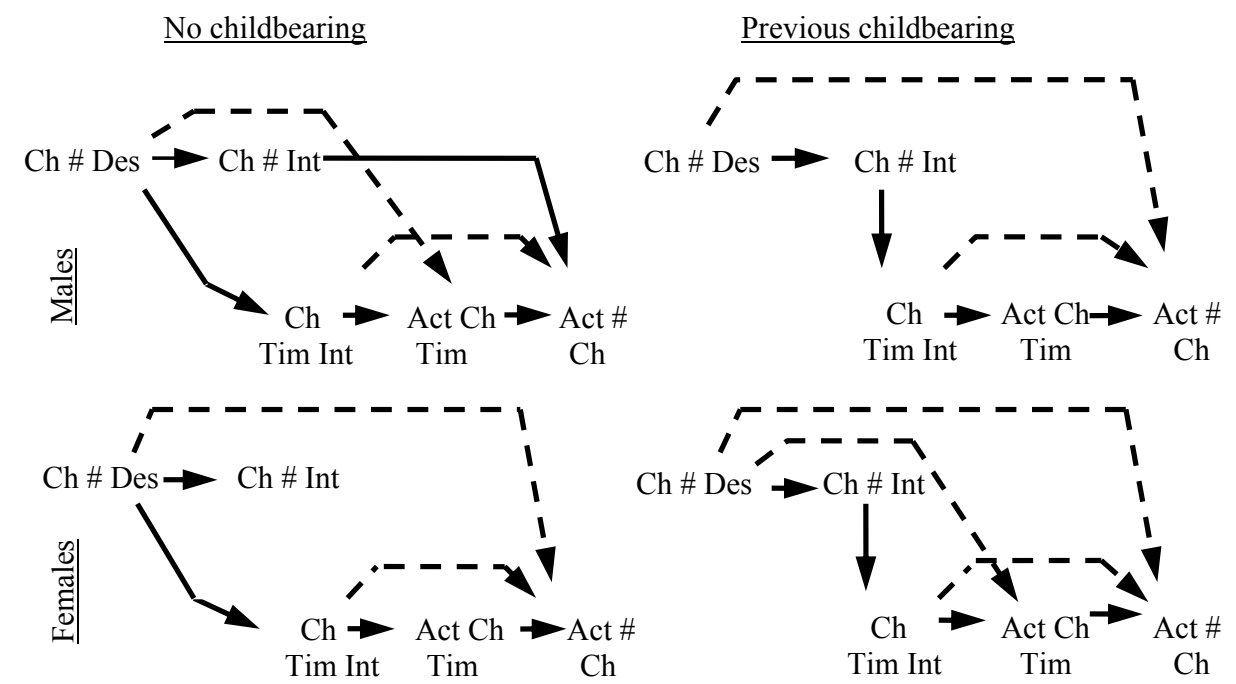

Notes: Solid lines indicate hypothesised connections and dashed lines represent non-hypothesised connections that appeared in the model. Adapted from Miller et al. (2010a). 
Note that in three out of four groups, child-number desires during the 1979-82 period directly predict the actual number of children born by 2002 . For males with no children, child-number intentions during the 1979-82 period children predict the actual number of children born by 2002. In order to quantify these results I estimated a standardised solution of the direct, indirect and total effects of child-number desires and intentions on the actual number of children born. These estimates, which were not reported in the original article, are shown in Table 3. They indicate that child-number intentions have virtually no total effects on the ultimate family size of the respondents across twenty years of follow-up, except for a small direct effect for parity zero males. In contrast, child-number desires have appreciable total effects on the ultimate family size, most of which are direct effects except for the parity zero males, and even for this latter group the indirect effects of desires exceed the total effects of intentions. Thus this study clearly demonstrates the potential for child-number desires to bypass their corresponding intentions and directly affect a long-term fertility outcome, raising serious questions about the predictive validity of intentions under some circumstances. Although the analyses discussed here do not allow an explanation of why the child-number desires of parity zero males are so different from the other three groups in not having long-term direct effects on family size, a clue may be that the direct effects column of the desires variable suggests a parity by sex interaction, with women of parity greater than zero having the largest direct effects and men of parity zero having no direct effects.

Note also in Figure 4 that the child-number desires of the youth with no children determine when they decide to start having children and their intentions play no role at all. Among the youth who have had a child, however, childnumber intentions become dominant in making the decision about the timing of the next child. Here again, there is some evidence that desires may bypass intentions in the flow of fertility decision-making, in this case indicating that the more primitive, affect-driven part of the dual motivational system plays a dominant role among those with no previous experience in childbearing. Whatever the explanation, it raises further questions about the predictive validity of child-number intentions at certain developmental points during the life course.

\subsection{Dimensions measured}

Recently, Jennifer Barber, Heather Gatny and I have begun to study ambivalent childbearing desires (2010). There are three interconnected challenges involved when undertaking this work, including theoretical, measurement and data-analytic issues. In this section I will briefly consider all three of these.

As mentioned in the background section, I divided childbearing motivational traits into positive and negative components. The theoretical rationale for doing this is that research has shown the brain to have separate reward and punishment systems for motivating behaviour (Cacioppo and Berntson 1994; Davidson and 
Irwin 1999; Rolls 1999). Because it is psychologically possible - and probably not uncommon - for individuals of reproductive age to simultaneously desire to have a(nother) child and desire not to have a(nother) child, these separate reward and punishment systems should, in theory, also apply to childbearing desires. I should note parenthetically that the same is not true for intentions because the decisionmaking and commitment aspect of intentions makes it psychologically next to impossible simultaneously to both intend to have a(nother) child and intend not to have a(nother) child.

How, then, would two dimensions of childbearing desires be measured? The traditional approach to measuring childbearing desires and intentions has been to measure a bipolar dimension by asking about the desire/intention to have a(nother) child and not to have another child with a single question. For example, I have used the following question to measure childbearing desires: "How do you feel about having a(nother) child sometime?" The respondent can answer using a five-point response scale, with categories ranging from "I definitely want to have a(nother) child" to "I definitely want not to have a(nother) child."

However, I have measured both positive and negative childbearing motivational traits on a unipolar dimension by asking respondents to first rate a list of the positive consequences of having children from "not desirable" to "highly desirable" and then to rate in a similar way a list of the negative consequences of having children from "not undesirable" to "highly undesirable" (Miller 1995). Much the same approach can be taken in creating two unipolar scales of childbearing desires.

In the Appendix of this article I have placed a questionnaire that demonstrates a method of priming respondents to answer questions about both positive and negative childbearing desires. The goal of priming in this case is to help the respondent come to the somewhat counter-intuitive notion that both positive and negative desires about some goal can be held simultaneously. It turns out empirically, however, that the respondents in our study of a large and diverse sample of female youths did not have any problem with this notion when we told the respondent that most people her age had both positive and some negative feelings about getting pregnant and having a child and then asked her first how much she wanted to get pregnant, using a scale from 0 to 5 , and then asked her how much she wanted to avoid getting pregnant, using a similar scale (Barber et al. 2010).

The measurement of two unipolar childbearing desires scales makes possible an analysis of the interaction between the positive and negative valences of desire. Figure 5 shows a graphic representation of the interaction of unipolar positive and negative dimensions of childbearing desires. Horizontally across the top of the figure is the six-point scale "Desire not to get pregnant" and vertically along the left side is the six-point scale "Desire to get pregnant". This arrangement generates four quadrants, with the respondents who fall in each quadrant being classified as follows, reading clockwise from the upper right: antinatal (low 
positive and high negative desires); ambivalent (high positive and high negative desires); pronatal (high positive and low negative desires); and indifferent (low positive and low negative desires).

\section{Figure 5:}

A graphic representation of the interaction of two unipolar pregnancy desire dimensions

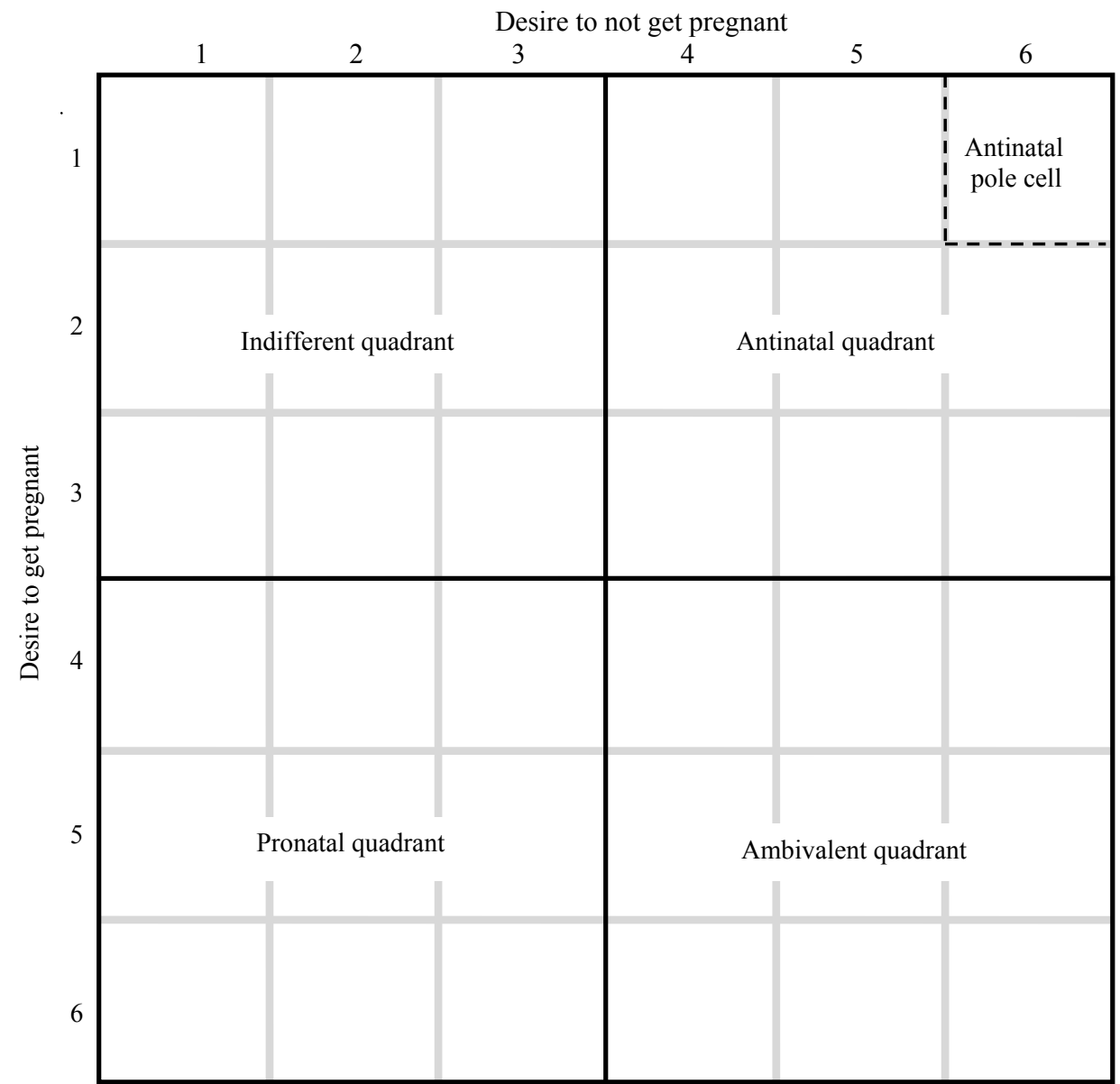

Notes: The two unipolar desire dimensions, one positive and the other negative, both vary from 1 to 6 . Adapted from Miller (2007)

Depending on the criteria used for respondent inclusion, 85 to $95 \%$ of our sample fell in the antinatal pole cell of the antinatal quadrant. However, enough women fell outside that cell to give three dummy variables based on each of the other three quadrants a significant hazard of pregnancy $(\mathrm{p}<0.01)$ and to give the dummy variable based on all the remaining cells of the antinatal quadrant a somewhat less significant hazard of pregnancy $(\mathrm{p}<0.05)$. This approach to 
studying the effects of childbearing desires on fertility outcomes suggests an entirely new family of variables that seem to play an important role in unintended fertility. Further, it indicates another way that childbearing desires can bypass intentions, thereby reducing their predictive validity.

\subsection{Effects on fertility satisfactions}

The first and certainly one of the most important ways of determining how happy someone is about having a child and how likely they are to be a good parent who feels satisfied in that role is to inquire about the wantedness of the pregnancy. For years, however, measuring pregnancy wantedness has been fraught with difficulty and much of this been a direct result of the conceptual confusion between desires and intentions that I mentioned in the introduction. Beginning in the 1970s, the US NSFG has used a 3-part system to classify pregnancies according to whether they were intended (also called wanted), mistimed, or unwanted. Unfortunately, this approach confounds a pregnancy that is desired before conception with one that is intended before conception. It also confounds a pregnancy that is desired before conception with one that is wanted afterward.

In order to determine the relative importance of childbearing desires and intentions on the wantedness of subsequent pregnancies, Jo Jones and I designed a study (Miller and Jones 2009) to answer the question: Do pre-conception intentions predict post-conception pregnancy wantedness above and beyond the effects of pre-conception desires and the perceived desires of the partner? Figure 6 shows the model we estimated, using data from a nationally representative sample of 2,299 women from the NSFG whose most recent pregnancy had occurred within the last three years. Table 3 gives the standardised parameter estimates and $\mathrm{R}^{2} \mathrm{~S}$ of the SEM obtained with the entire sample. In the row for the wantedness outcome variable, one can see that both pre-conception desires and the perceived pre-conception desires of the partner predict postconception pregnancy wantedness, but that intentions do not, in fact, predict wantedness.

We also conducted a number of moderator variable analyses to determine if there were subgroups within the overall sample where intentions did predict postconception pregnancy wantedness. We found a number of instances where they did, although the effects were relatively small compared to the effects of desires. The subgroups in those instances involved three different respondent contexts: mating, reproduction and socio-economic status. The common theme across these three contexts seemed to be the woman's potential concern about her ability to achieve her own reproductive desires. Our findings suggested that when the woman had confidence in her partner's commitment, her own and her partner's fecundity and her power to make reproductive decisions, the sense of control this gave her slightly increased the value (i.e. the wantedness) of a pregnancy above and beyond what she felt simply on the basis of her own desires. 
Figure 6:

The hypothesised model that was tested with the NSFG 2002 data

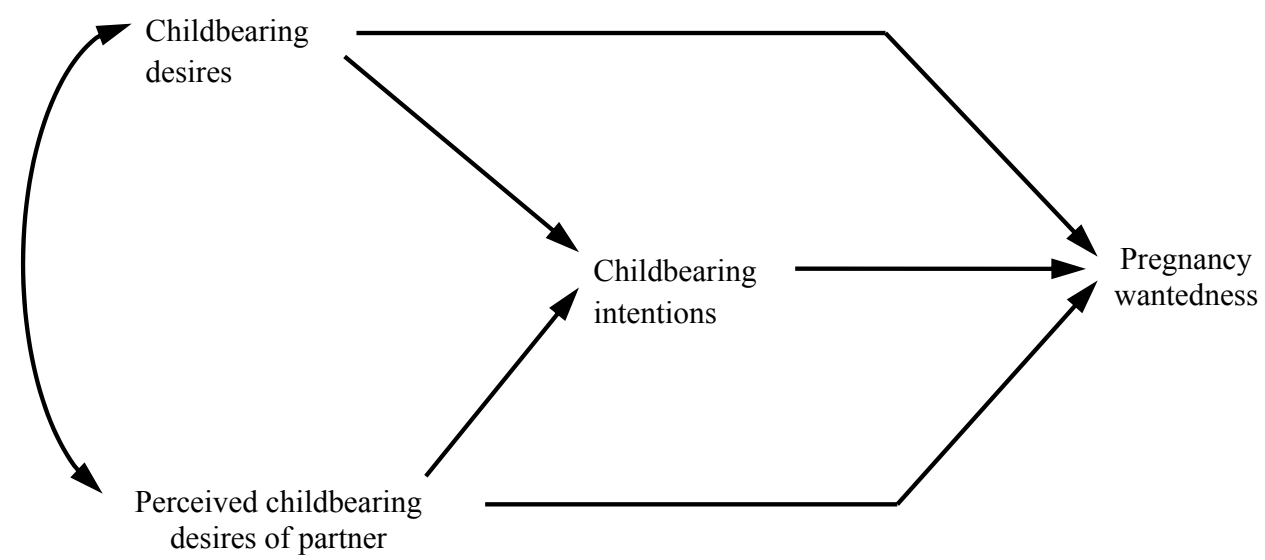

Note: Adapted from Miller and Jones (2009)

Table 3:

Standardised direct, indirect and total effects of child-number desires and intentions on actual number of children for parity $=0$ and parity $>0$ males and females in the NLSY structural equation model represented in Figure 4

\begin{tabular}{lllllll}
\hline & \multicolumn{5}{c}{ Predictors of actual number of children and their effects } \\
\hline $\begin{array}{l}\text { Sex and } \\
\text { parity } \\
\text { groups }\end{array}$ & $\begin{array}{l}\text { Child-number desires: } \\
\text { direct } \\
\text { effects }\end{array}$ & $\begin{array}{l}\text { indirect } \\
\text { effects }\end{array}$ & $\begin{array}{l}\text { total } \\
\text { effects }\end{array}$ & $\begin{array}{l}\text { Child-number intentions: } \\
\text { direct } \\
\text { effects }\end{array}$ & $\begin{array}{l}\text { indirect } \\
\text { effects }\end{array}$ & $\begin{array}{l}\text { total } \\
\text { effects }\end{array}$ \\
\hline $\begin{array}{l}\text { Parity=0 } \\
\text { males }\end{array}$ & .00 & .13 & .13 & .09 & .00 & .09 \\
$\begin{array}{l}\text { Parity=0 } \\
\text { females }\end{array}$ & .15 & .01 & .16 & .00 & .00 & .00 \\
$\begin{array}{l}\text { Parity }>0 \\
\text { males }\end{array}$ & .18 & .00 & .18 & .00 & .00 & .00 \\
$\begin{array}{l}\text { Parity }>0 \\
\text { females }\end{array}$ & .32 & .06 & .38 & .00 & .01 & .01 \\
\hline
\end{tabular}

\section{Discussion}

The differences between fertility desires and intentions reviewed above have implications for our theoretical understanding of fertility motivation. I have shown that childbearing and child-number desires have properties that distinguish them in important ways from childbearing and child-number intentions, supporting the argument that the two types of fertility desires must not be confounded with their two corresponding fertility intentions. Specifically, the reviewed studies provide evidence that fertility desires, compared with intentions, 
represent a more proximate expression of the genetically-based motivations that drive reproduction. They also provide evidence that fertility desires are far more central than intentions in the determination of post-conception pregnancy wantedness and, presumably, of many of the later parental motivations that play a role in favourably supporting child development. It is therefore not unreasonable to view fertility desires as the conduit through which the evolution of the human organism affects the adaptiveness and happiness of each new child that is born and of the future generations to which all such children may contribute. Intentions, on the other hand, may be viewed as the conduit for the current contexts of individual actors, as well as the risks and rewards that they perceive in those contexts and then weigh in the fertility decision-making process.

The importance of fertility desires not only as a key construct in the motivational sequence leading to pregnancy but as a conduit of biological 'wisdom' between generations is underscored by the evidence that desires may bypass intentionality and act directly on behaviour to influence fertility outcomes. I have considered three examples of this bypass phenomenon: first, when the desires of for a certain number of children act not only through the intentions of the T-D-I-B motivational sequence, but also independently to assert their influence across twenty years of behaviour to determine the final number of children born; second, when the actors involved have no prior and, as a result, have desires that act strongly outside the usual T-D-I-B process; and third, when positive and negative childbearing desires are configured so that in interaction they express an ambivalent, indifferent or pronatal motivational profile that puts women at risk for an unintended pregnancy.

All of the properties of fertility desires and intentions findings that have been explored here deserve considerable further research. In addition to the need for investigations that confirm and extend the genetic findings I have reported, there are a number of specific research questions about the genetic determinants of fertility desires that need to be addressed. As motivational traits are antecedent to desires in the T-D-I-B framework, it is important to know whether their inclusion in behavioural genetic studies, as they were in the molecular genetics study considered in Section 3.1, reduces or eliminates the proportion of genetic variance attributable to fertility desires. Because both childbearing and child-number desires appear to have genetic antecedents and both are distinct predictors within the T-D-I-B framework, it is also important to conduct studies clarifying the relationship between the genetic antecedents of these two types of fertility desires. Finally, it is important in molecular genetic studies to have much more hypothesis-driven research that is solidly based on an understanding of the specific motivations that drive childbearing and the specific neurochemistry that underlie those motivations. Further research is also needed on the bypass phenomenon in which fertility desires act directly on outcomes rather than through their corresponding intentions, including when those direct effects act over both short and long intervals. Although there have been a number of recent 
studies of changes in both fertility intentions (e.g. Liefbroer 2009; Iacovou and Tavares 2010; and Ni Bhrolcháin et al. 2010) and desires (e.g. Adsera 2006; Heiland et al. 2008), it is rare for the two to be studied together (but see Hagewen and Morgan 2005). What is required to adequately examine the relationship between fertility desires and intentions and under what conditions the former bypass the latter are data that include information about both constructs collected simultaneously, as well as the investigator's use of both theory and measurement that clearly recognise the important distinctions between desires and intentions, together with the fundamental role that desires have in the formation of intentions.

Although motivational ambivalence has long been recognised as being an important antecedent of unintended pregnancy, especially in adolescents (Zabin 1999), it is only recently that systematic examination of this phenomenon has begun (Barber et al. 2010; Sheeder et al. 2010; McQuillan et al. 2011). The new measurement and conceptual approaches discussed in Section 3.3 should enable a different approach to how data about childbearing desires are collected. This, in turn, should lead to more studies with data that specifically address the phenomenon of ambivalence and the related state of indifference, ultimately generating a more complete understanding of unintended pregnancy.

The final area that deserves further research involves the question of whether pre-conception intentions increase the wantedness of a pregnancy beyond that contributed by pre-conception desires. First, the findings of Miller and Jones (2009) for women need confirmation. Optimally such a study would be prospective in design, thereby avoiding retrospective rationalisation and related distortions. Equally important are studies of whether the minor role of preconception intentions in wantedness holds for men and whether it holds for cultures outside the USA, as well as for groups and situations not studied by Miller and Jones.

The construct differences between fertility desires and intentions that I have described also have important policy implications. A major concern among many European policy makers in recent years has been the perception that a sizable proportion of couples fail to realise their intended fertility, resulting in what has been called the gap between intended and actual fertility.

Although much of the literature addressing the gap concept actually defines it in terms of the difference between desired or ideal fertility and actual fertility (Chesnais 2000; Goldstein et al. 2003; Philipov et al. 2009), a great deal of recent research has operationally defined it in terms of the difference between intended or expected fertility and actual fertility (Liefbroer 2009; Philipov et al. 2009), in part because intentions are viewed as more realistic than desires but at the same time as good indicators of them (Philipov et al. 2009). As a result, the Theory of Planned Behaviour (Ajzen 1991, 2005), which offers a highly cognitive, rationalchoice approach to the antecedents of fertility behaviour, has become the dominant theoretical framework used in gap-related research at the micro level. 
However, based on the theory implicit in the T-D-I-B framework, I would argue that in using intentions to define the gap, one is measuring something that already reflects adjustments and compromises to what individuals would really like, changes that are a result of situational constraints and internal conflicts. If the purpose of policy is really to help individuals satisfy their true reproductive goals, then the most important gap to be studied is the one defined in terms of fertility desires. A reasonable solution to this problem is to define two gaps: one between intended family size and actual family size and the other between desired family size and intended family size. For the purposes of this discussion, I will call these the intended-actual gap and the desired-intended gap. A third type of gap could be defined in terms of the difference between desired and actual family size, although that third gap is simply the sum of the first two gaps. However, I believe that each of the first two gaps has its own unique value for policy purposes, so it is likely that using a gap based on the sum of the first two would tend to obscure those unique values. This does not mean, of course, that one could not simultaneously use both of the first two gaps as predictors in prediction or projection studies.

An important issue that bears on the two gaps I have suggested is that fertility desires and intentions are both developmental in nature. This is implicit in Lee's (1980) discussion of family size as a moving rather than a fixed target and in Liefbroer's (2009) use of the life-span theory of control in Heckhausen and Schultz (1995) to examine changes in expected fertility. Thus both fertility desires and fertility intentions can be expected to change over reproductive careers, and these changes can be expected not only in response to external, social and economic constraints but also to internal, maturational factors, including decisions made about activities that are competitive with childbearing. A fundamental aspect of this broad developmental process is that fertility decisions are made one birth at a time, with each birth having a feedback effect upon desires and intentions (Miller and Pasta 1995) and each major life decision within such behavioural domains as education, employment and partner relationships having its own important effect as well. The net effect of this commonly experienced series of events and decisions may be that both family size desires and intentions undergo upward and/or downward changes across the roughly 30 year reproductive span. Liefbroer (2009) has demonstrated that this pattern is true for intentions, and it seems very probable that much the same holds for desires. Thus in addition to the periodic increases and decreases in the two gaps caused by these changes in fertility desires and intentions, both gaps could be expected to demonstrate a downward trend across the reproductive span that would probably be apparent for most individuals and would almost certainly be so at the aggregate level.

Let me consider what these trends might look like for both types of gap if desired, intended and actual family size were measured in a hypothetical sample, say, every five years from 15 to 45 . The intended-actual gap may be said to reflect 
the extent to which individuals have realised their family size intentions at a given point in time. We would expect to see a progressive narrowing of this gap for the entire sample until the end of the reproductive span as a result of social and economic constraints on individuals and the decisions they make about activities that are competitive with childbearing. At that point, given that no one can intend fewer children than they already have, the gap would essentially disappear. Thus for the purpose of guiding public policy, the intended-actual gap is most useful as an estimate of final family size no matter when during the reproductive span data are collected. Of course, the accuracy of those estimates will be progressively less accurate as the time of projection across the reproductive span lengthens. However, the evidence discussed in Section 3.2 for the direct prediction of final family size across a 20 -year period by child-number desires suggests that the supplementary use of fertility desires data might well improve long-term projection estimates.

The desired-intended gap, in contrast, may be said to reflect the extent to which individuals have modified their family size intentions away from their family size desires as a result of external constraints and decisions about competitive activities. If we again think about how this second type of gap would change in the same hypothetical sample across the reproductive span, we would also expect to see a trend for the entire sample toward smaller family size desires and intentions for the same reasons cited above regarding the first type of gap. However, because desires are appreciably influenced by enduring motivational traits and the genetic factors that underlie them, both of which factors are relatively little influenced by social and economic constraints and decisions about competitive activities, we would expect the downward trend for family size desires to have a much shallower slope over time compared with that of the intentions trend. For these reasons, the same degree of convergence toward zero observed with the intended-actual gap would not be likely for the desiredintended gap. These considerations suggest that it is the desired-intended gap that may best indicate the problem areas at which social policy should be directed to help individuals strive for the family size they intrinsically desire.

The above discussion focused on social policy as it relates to two primary motivational determinants of family size, namely child-number desires and intentions. The issues that affect these two components of motivation are longterm ones; they unfold across the reproductive spans of the individuals involved. I turn briefly to a discussion of social policy and two motivational determinants that are more relevant to the short term, namely childbearing desires and intentions. In the USA, two major and related sources of concern among family planning service providers are the frequency of unintended pregnancies and the large number of induced abortions. The measurement and conceptual approaches to childbearing desires that I discussed in Section 3.3 provide new tools for understanding how the interaction of positive and negative desires lead to motivational ambivalence, indifference and pronatalism, with obvious 
implications for reducing our ignorance about the origins of unintended pregnancies. Once these tools have been used in large systematic studies, we should have a sufficient knowledge base to develop policies that will support interventions to reduce adolescent and unintended pregnancies through schools, clinics and public information forums. However, any such policies will also have to be informed by an understanding that it is the desire for a child - not the intention to have one - that plays a prominent role in determining the wantedness of the pregnancy. At the same time, this understanding must itself be informed by any knowledge we develop about special cases in which intentions give added value to a pregnancy for certain groups.

\section{References}

Adsera, A. 2006. An economic analysis of the gap between desired and actual fertility: the case of Spain. Review of the Economics of the Household 4(1).

Ajzen, I. 1991. The theory of planned behavior. Organizational Behavior and Human Decision Processes 50: 179-211.

Ajzen, I. 2005. Attitudes, personality, and behaviour. Second edition, Maidenhead, Berkshire, England: Open University Press.

Barber, J.S., W.B. Miller and H.H. Gatny 2010. The desire to become pregnant and the desire to avoid pregnancy: ambivalence, indifference, pronatalism and antinatalism. Paper presented at the REPRO conference "From intentions to behaviour: reproductive decision-making in a macro-micro perspective", Vienna, Austria, 2-3 December 2010. http://www.oeaw.ac.at/vid/in2b, accessed on 1 January 2011.

Cacioppo, J.T. and G.G. Berntson 1994. Relationships between attitudes and evaluative space: a critical review, with emphasis on the separability of positive and negative substrates. Psychological Bulletin 115(3): 401-423.

Chesnais, J.-C. 2000. Determinants of below replacement fertility. In Below replacement fertility. Population Bulletin of the United Nations, Special Issue 1999, 40/41: 126-136.

Davidson, R.J., W. Irwin 1999. The functional neuroanatomy of emotion and affective style. Trends in Cognitive Sciences 3(1): 11-21.

Goldstein, J., W. Lutz and M. R. Testa 2003. The emergence of subreplacement family size ideals in Europe. Population Research and Policy Review 22: 479-496.

Hagewen, K. J. and S. P. Morgan 2005. Intended and ideal family size in the United States, 1970-1998. Population and Development Review 31(3): 507-527.

Heckhausen, J. and R. Schultz 1995. A life-span theory of control. Psychological Review 102: 284-304.

Heiland, F., A. Prskawetz and W. Sanderson 2008. Are individuals' desired family sizes stable? Evidence from West German panel data. European Journal of Population 24(2): 129-156.

Iacovou, M and L.P. Tavares 2010. Yearning, learning and conceding: (some of) the reasons people change their childbearing intentions. Institute for Social and Economic Research Working Paper 2010(22). University of Essex. Available at www.iser.essex.ac.uk 
Jorescog, K.G. and D. Sorbom 1996. LISREL 8: User's reference guide. Chicago: Scientific Software International.

Lee, R. 1980. Aiming at a moving target: period fertility and changing reproductive goals. Population Studies 34(2): 205-226.

Liefbroer, A.C. 2009. Changes in family size intentions across young adulthood: a lifecourse perspective. European Journal of Population 25(4): 363-386.

McQuillan, J., A.L. Greil and K.M. Shreffler 2011. Pregnancy intentions among women who do not try: focusing on women who are okay either way. Maternal and Child Health Journal 15: 178-187.

Miller, W.B. 1986. Proception: an important fertility behavior. Demography 23(4): 579-594.

Miller, W.B. 1994. Childbearing motivations, desires, and intentions: a theoretical framework. Genetic, Social, and General Psychological Monographs 120(2):223-258.

Miller, W.B. 1995. Childbearing motivation and its measurement. Journal of Biosocial Science 27: 473-485.

Miller, W.B. 2007. The interaction of positive and negative childbearing desires: a graphic model. Available at www.tfri.org

Miller, W.B. 2011. Why we have children: building a unified theory of the reproductive mind. Available at www.tfri.org

Miller, W.B. and J.L. Rodgers 2001. The ontogeny of human bonding systems. Boston: Kluwer.

Miller, W.B. and J. Jones 2009. Modeling the motivational antecedents to pregnancy intendedness and wantedness in the 2002 NSFG. Journal of Population Research 26(4): 327-357.

Miller, W.B. and D.J. Pasta 1993. Motivational and nonmotivational determinants of child-number desires. Population and Environment 15(2): 113-138.

Miller, W.B. and D.J. Pasta 1994. The psychology of child timing: a measurement instrument and a model. Journal of Applied Social Psychology 24(3): 221-250.

Miller, W.B. and D.J. Pasta 1995. How does childbearing affect fertility motivations and desires? Social Biology 42(3-4): 185-198.

Miller, W.B. and D.J. Pasta 1996. The relative influence of husbands and wives on the choice and use of oral contraception, a diaphragm, and condoms. Journal of Applied Social Psychology 26: 1749-1774.

Miller, W.B., D.J. Pasta, J. MacMurray, D. Muhleman and D.E. Comings 2000. Genetic influences on childbearing motivation: further testing a theoretical model. In Genetic. influences on human fertility and sexuality, ed. J.L. Rodgers, D.C. Rowe and W.B. Miller, 35-66. Boston: Kluwer.

Miller, W.B., L.J. Severy, and D.J. Pasta 2004. A framework for modeling fertility motivation in the dyad. Population Studies 58(2): 193-205.

Miller, W.B., D.J. Pasta and J.L. Rodgers 2010a. The fertility motivations of youth predict later fertility outcomes: a prospective analysis of NLSY data. Biodemography and Social Biology 56(1): 1-23.

Miller, W.B., D.E. Bard, D.J. Pasta and J.L. Rodgers 2010b. Biodemographic modeling of the links between fertility motivation and fertility outcomes in the NLSY79. Demography 47(2): 393-414.

Neale, M.C., S.M. Boker, G. Xie and H.H. Maes 2003. Mx: Statistical modeling. Sixth edition, Richmond, Department of Psychiatry, Virginia Commonwealth University. 
Ní Bhrolcháin, M.N., E. Beaujouan and A. Berrington 2010. Stability and change in fertility intentions in Britain, 1991-2007. Population Trends 141: 1-23.

Philipov, D., O. Thévenon, J. Klobas, L. Bernardi and A.C. Liefbroer 2009. Reproductive decision-making in a macro-micro perspective (REPRO): a state of the art review. A working paper of the European Commission within the Seventh Framework Programme under the Socio-economic Sciences and Humanities theme. Available at http://www.oeaw.ac.at/vid/download/edrp_1_09.pdf

Rolls, E.T. 1999. The brain and emotion. Oxford: Oxford University Press.

Sheeder, J., S.B. Teal, L.A. Crane and C. Stevens-Simon 2010. Adolescent childbearing ambivalence: Is it the sum of its parts? Journal of Pediatric and Adolescent Gynecology 23: 86-92.

Zabin, L.S. 1999. Ambivalent feelings about parenthood may lead to inconsistent contraceptive use and pregnancy. Family Planning Perspectives 31: 250-251.

\section{Appendix}

\section{Rating the Desire to Get Pregnant and Have a Child and the Desire Not to Get Pregnant and Have a Child}

We are interested in how you felt about having a baby just before the last time you got pregnant. As you know, getting pregnant and having a baby is a big event, one that has a lot of consequences. Some of these consequences, perhaps most of them may be positive to you. On the other hand, some of these consequences, perhaps most of them may be negative to you. It all depends on who you are and what the most important things are to you at this point in your life. Most people have at least some positive and some negative feelings about getting pregnant and having a child. For this reason we are going to ask you to think back for a moment to just before the last time you got pregnant and try to recall all the feelings you had about the consequences for you at that time of getting pregnant and having a baby.

First, we are interested in positive feelings. Some of the positive feelings that people have about getting pregnant and having a child are related to:

- Feeling a baby move and kick inside me (my partner);

- Holding and cuddling a baby;

- Strengthening my marriage (relationship) through a child;

- Playing with my child;

- Teaching my child;

- Feeling more complete as a woman (man).

Of course, there were probably other positive consequences of getting pregnant and having a baby that were important to you just before the last time you got pregnant and we want you to think about those as well. Now, taking into account all the positive consequences that were important to you, how would you rate your desire to get pregnant and have a child at that time? (Show rating scale 
and point to each answer as you read:) Rate your desire a 0 if you had no desire to get pregnant and have a child, rate it a 1 if you had a small amount of desire to get pregnant and have a child, rate it a 2 if you had a moderate amount of desire to get pregnant and have a child, rate it a 3 if you had a large amount of desire to get pregnant and have a child, and rate it a 4 if you had a very large amount of desire to get pregnant and have a child.

Second, we are interested in negative feelings. Some of the negative feelings that people have about getting pregnant and having a child are related to:

- (Watching my wife/partner experience) Experiencing the discomforts of pregnancy and childbirth;

- Having to put up with a needy and demanding baby;

- Not having a stable marriage (relationship) for raising a baby;

- Not being able to do some of the other things I want to do, like working, going to school, or travelling;

- Worrying that I was not being a good parent;

- Being afraid that there would not be enough money to take good care of a child.

And again, there were probably other negative consequences of getting pregnant and having a baby that were important to you just before the last time you got pregnant and we want you to think about those as well. Now, taking into account all the negative consequences that were important to you, how would you rate your desire not to get pregnant and have a child at that time? (Show rating scale and point to each answer as you read:) Rate your desire a 0 if you had no desire not to get pregnant and have a child, rate it a 1 if you had a small amount of desire not to get pregnant and have a child, rate it a 2 if you had a moderate amount not to get pregnant and have a child, rate it a 3 if you had a large amount not to get pregnant and have a child, and rate it a 4 if you had a very large amount of desire not to get pregnant and have a child .

\section{Rating scale}

$\begin{array}{ccccc}\begin{array}{c}\text { No } \\ \text { amount } \\ \text { of desire }\end{array} & \begin{array}{l}\text { Small } \\ \text { amount } \\ \text { of desire }\end{array} & \begin{array}{l}\text { Moderate } \\ \text { amount } \\ \text { of desire }\end{array} & \begin{array}{l}\text { Large } \\ \text { amount } \\ \text { of desire }\end{array} & \begin{array}{c}\text { Very Large } \\ \text { amount } \\ \text { of desire }\end{array}\end{array}$

